\title{
A nationwide study of the epidemiology of relapsing polychondritis
}

This article was published in the following Dove Press journal:

Clinical Epidemiology

23 June 2016

Number of times this article has been viewed

\section{Anna Horváth' \\ Nóra Páll ${ }^{2}$ \\ Katalin Molnár ${ }^{1}$ \\ Tamás Kováts ${ }^{3}$ \\ György Surján ${ }^{3}$ \\ Tamás Vicsek ${ }^{4,5}$ \\ Péter Pollner ${ }^{2,4}$}

'3rd Department of Internal Medicine, Semmelweis University, ${ }^{2}$ Regional Science Center, Faculty of Science, Eötvös Loránd University, ${ }^{3} \mathrm{National}$ Healthcare Service Center, ${ }^{4}$ MTAELTE Statistical and Biological Physics Research Group, ${ }^{5}$ Department of Biological Physics, Eötvös Loránd University Budapest, Hungary
Correspondence:Anna Horváth 3rd Department of Internal Medicine. Semmelweis University, Kútvölgyi út 4, $\mathrm{H}-\mathrm{I}$ I 25 Budapest, Hungary

Tel +362066323I9

Fax +36 I 355825 I

Email horvath.anna@med.semmelweisuniv.hu
Objective: Relapsing polychondritis (RP) is a rare autoimmune inflammatory disease that attacks mainly cartilaginous structures or causes serious damage in proteoglycan-rich structures (the eyes, heart, blood vessels, inner ear). This study shows results regarding the epidemiology, progression, and associations of this highly variable disease by collecting all cases from a 124-million-person-year Central European nationwide cohort.

Methods: We used the Hungarian Health Care Database to identify all persons with possible RP infection. We followed patients who had International Classification of Diseases 10th edition code M94.1 at least once in their inpatient or outpatient records between January 1, 2002 and December 31, 2013 in Hungary. We classified these patients into disease severity groups by their drug consumption patterns between January 1, 2010 and December 31, 2013. We analyzed the regional distribution of RP incidences as well. Overall maps of comorbidity are presented with network layouts.

Results: We identified 256 patients with RP among cumulatively 11.5 million registered inhabitants. We classified these patients into four severity classes as "extremely mild" (n=144), "mild" $(n=22)$, "moderate" $(n=41)$, and "severe" $(n=4)$. Two additional groups were defined for patients without available drug data as "suspected only" $(\mathrm{n}=23)$ and "confirmed but unknown treatment" $(n=22)$. The age and sex distributions of patients were similar to worldwide statistics. Indeed, the overall survival was good ( $95 \%$ confidence interval for 5 years was $83.6 \%-92.9 \%$ and for 10 years was $75.0 \%-88.3 \%$ which corresponds to the overall survival of the general population in Hungary), and the associations with other autoimmune disorders were high (56\%) in Hungary. Almost any disease can occur with RP; however, the symptoms of chromosomal abnormalities are only incidental. Spondylosis can be a sign of the activation of RP, while Sjögren syndrome is the most frequent autoimmune association. Regional distribution of incidences suggests arsenic drinking water and sunlight exposure as possible triggering factors.

Conclusion: The good survival rate of RP in Hungary is probably associated with the early diagnosis of the disease.

Keywords: cohort of Hungary, incidence rate, severity prevalence, autoimmune comorbidity, environmental factors, network representation

\section{Introduction}

Relapsing polychondritis (RP) is a rare autoimmune disease. ${ }^{1}$ While diagnostic criteria are well established, ${ }^{2-4}$ there are no population-based studies on severity, comorbidity, and environmental effects. RP affects all ages, with reports of cases involving children younger than 3 years of age and adults older than 85 years. ${ }^{5}$ Pregnancy does not seem to influence the course of the disease. ${ }^{6}$ The most typical patient with polychondritis is middle aged (between 45 and 55 years), and the disease occurs equally in males and females. ${ }^{6}$ The 10 -year survival 
rate reported in 1986 was $55 \%,{ }^{4}$ whereas in 1998 , another study showed that $94 \%$ of patients were alive after 8 years. ${ }^{7}$

$\mathrm{RP}$ is an inflammatory disease, associated with HLA DR4 allele. ${ }^{8}$ There is a marked variability in the pathogenesis. The complex processes that may be observed include reduction of immunoregulatory cells, appearance of inflammatory cells, antibodies attacking cartilage tissue elements like type-II, type-IX, and type-XI collagen and matrilin1, changes in cytokine profiles, deposition of immune complexes, and insufficient tissue regeneration. ${ }^{9-16}$

Clinical manifestations range from benign occurrence without visceral involvement through a smoldering status with changing severity up to a fulminant, occasionally fatal downhill course. RP can be induced by toxins, ${ }^{17}$ infections, ${ }^{18}$ injuries, ${ }^{19}$ or glucosamine-chondroitin supplement initiation. ${ }^{20}$ Genetic susceptibility, ${ }^{12}$ relationship with clonal stem cell disorders (myelodysplasia syndrome), ${ }^{21,22}$ and association with other autoimmune diseases ${ }^{5,23}$ are also contributing factors to the etiology of the disease.

$\mathrm{RP}$ is treated with several therapeutic methods according to different manifestations of the disease. Less severe symptoms like moderate auricular, nasal chondritis and arthralgia are usually treated with nonsteroid anti-inflammatory drugs (NSAIDs). Dapsone is used in several countries, but it is not available in Hungary. Colchicine may be effective in these patients. Organ-threatening disease, including ocular or laryngotracheal involvement, severe polychondritis, or systemic vasculitis requires systemic corticosteroids. In patients intolerant to or unresponsive to steroid therapy, or in whom a steroid-sparing therapy is required due to the chronic course of the disease, immunosuppressants are needed. In these cases, methotrexate, azathioprine, cyclosporine, and chlorambucil may be used. ${ }^{24,25}$ Intravenous cyclophosphamide and plasmapheresis are used in life-threatening situations, or in organ-threatening disease including acute airway obstruction or glomerulonephritis. ${ }^{26}$ A number of biologics targeting the B cells and the pathways of cell-mediated immunity (anti-CD4, anti-CD20, anti-TNF agents, IL-1 receptor antagonist, CTLA4-IgG1 fusion protein, or anti-IL-6 receptor antibody) are applied if RP is not responding to other medical therapy. ${ }^{27,28}$ In this paper, we report yearly incidence rate, sex ratios, prevalence of severity classes, comorbidity network, and possible environmental triggering factors using health care registries of Hungary.

\section{Methods}

\section{Database, time interval, and population}

Data from the Hungarian Global Financial Healthcare Database (HGFHD) were used to identify all persons (Hungarian residents or foreigners) who were residing and treated in
Hungary in the public health care system between January 1, 2002 and December 31, 2013. The database has cumulatively registered 11.5 million individuals with 124 million person-years of follow-up of hospital admissions and contacts in outpatient clinics. This population has a life expectancy of 72 years for males and 79 years for females where the leading death causes are the diseases of the circulatory system ( $\mathrm{n}=62,979 ; 50 \%$ of the total number of deaths), cancer $(n=33,274 ; 26 \%$ of the total number of deaths), and diseases of the respiratory system $(n=7,009 ; 5.53 \%$ of the total number of deaths). Each reported visit is marked with one or more diagnoses according to the International Classification of Diseases 10th edition (ICD10). ${ }^{29}$ Data in this database are collected primarily for financial purposes, though the diagnoses are always specified by the visited physician, who is responsible for correctness of the data.

The second data source of the study was the Hungarian Drug Consumption Database (HDCD), which registers information about Rx (prescription linked) and reimbursed medicines obtained in pharmacies between January 1, 2010 and December 31, 2013. The main deficiency of HDCD is that it does not concern over the counter and unreimbursed drug obtainment. Furthermore, it does not include drugs taken during inpatient care nor provide information about real medicine consumption.

A unique social security number assigned to all residents in Hungary allows record linkage of databases at the individual level because both databases are maintained by the National Health Insurance Fund.

We constructed a patient pool $(n=256)$ from the HGFHD by selecting people with outpatient or inpatient visits marked with RP (ICD10 = M94.1) either as a primary or as an associated diagnosis code. Some of the patients $(n=23)$ were not considered in the epidemiological statistics because their symptoms had been determined by laboratory, pathology, computed tomography, or magnetic resonance diagnostics, but the disease was not confirmed later by specialists.

Due to the retrospective nature of the study, this study was deemed exempt by Hungarian Ministry of Health legislation regarding encrypted databases for research purposes in Hungary. Databases used in the study contain encrypted patient personal information to protect privacy and provides researchers with anonymous identification numbers. Therefore, patient written informed consent is not required to access the database for research purposes.

\section{Severity classes}

We used medication treatment data from HDCD for distinguishing severity levels of the disease. From the combinations 
of the three main types of drugs (NSAID, steroid, immunosuppressant $)^{30}$ and from the time delay between the drug obtainment and the clinical diagnosis of RP, we grouped the observed RP cases into four progression levels. Patients in the study population were classified according to the level of the most severe case in their history in HDCD.

Since HDCD is available for the years 2010-2013, it provides information for the end of the histories of $n=211$ individuals, which corresponds to $90.6 \%$ of the confirmed RP population.

\section{Levels of disease severity and hospitalization length}

Two further classes were constructed for the people who either never had a confirmed RP or had no records in the HDCD. The members of these classes were included neither in the severity versus treatment-duration analysis in this Section.

According to the mentioned guidelines, the whole ( $\mathrm{n}=256)$ RP population was classified as follows:

- Suspected only ( $n=23)$ : Patients who had M94.1 record in the patient history, but these records were defined by laboratories or pathology or CT without further clinical confirmation. We considered these cases as instances of clinician's suspicion where the result did not support previous assumptions. Therefore, the HDCD records of patients in this class were irrelevant. This class was excluded from severity statistics and analysis.

- Confirmed only ( $n=22)$ : Patients who did not have records in the drug obtainment database but had clinically confirmed RP diagnoses. This class was excluded from severity statistics and analysis. Here, an earlier level of severity was inferred from the frequency of patient-doctor contacts.

Table I Main descriptive measures for the severity levels: main central measures for the age distribution and for the distribution of treatment days, and sex ratio in different severity levels

\begin{tabular}{lllll}
\hline & $\begin{array}{l}\text { Extremely } \\
\text { mild } \\
(\mathbf{n}=\mathbf{I 4 4})\end{array}$ & $\begin{array}{l}\text { Mild } \\
(\mathbf{n}=\mathbf{2 2})\end{array}$ & $\begin{array}{l}\text { Moderate } \\
(\mathbf{n}=\mathbf{4 1})\end{array}$ & $\begin{array}{l}\text { Severe } \\
(\mathbf{n}=\mathbf{4})\end{array}$ \\
\hline Males & $37 \%$ & $41 \%$ & $44 \%$ & $75 \%$ \\
Females & $63 \%$ & $59 \%$ & $56 \%$ & $25 \%$ \\
Average age (years) & 55.7 & 58 & 51.1 & 55 \\
Standard deviation of age & 15 & 12 & 14 & 18 \\
(years) & & & & \\
Daynum average & $\mathrm{I}$ & 15 & 32 & 41 \\
Daynum standard deviation & 4 & 22 & 35 & 19 \\
Min (daynum) & 0 & 0 & 1 & 15 \\
Q25 (daynum) & 0 & 1 & 8 & 36 \\
Q50 (daynum) & 0 & 7 & 16 & 44 \\
Q75 (daynum) & $\mathrm{I}$ & 13 & 49 & 48 \\
Max (daynum) & 20 & 91 & 128 & $6 \mathrm{I}$ \\
\hline
\end{tabular}

Abbreviations: Daynum, number of days of hospitalization; Min, minimum; Max, maximum.
- Confirmed and treated with drugs in HDCD range $(\mathrm{n}=211)$ : This group was selected by the condition that RP was diagnosed by a clinician and the patient had obtained medicine at least once according to the HDCD. We subdivided this group by treatment patterns into severity groups ranging from extremely mild to severe. In order to confirm that the patient obtained the medicine for RP, we only took those drugs into account which were bought within 30 days after an outpatient/inpatient visit marked with RP diagnosis (ICD10 = M94.1). The severity classes were the following:

$\circ \quad 0$ - extremely mild $(n=144)$ : The largest subgroup consisted of patients who met any of the criteria given as follows:

- Had an RP diagnosis after the start of HDCD (January 1, 2010) and obtained medicine, but the drug is not classified for RP treatment.

- Obtained an RP-related medicine but before the $\mathrm{RP}$ diagnosis. Note that there are no drugs targeting RP exclusively; therefore, the patient can take them for other diseases as well, for example, for other autoimmune diseases.

- Patients who were last diagnosed with RP 1 month before the start of HDCD (diagnosed before December 1, 2009) and had at least one record in the HDCD. We assumed that the patient either had healed or did not need medical control anymore. Therefore, the progression should have been at a very mild stage.

- 1 - mild ( $\mathrm{n}=22)$ : Patients who bought NSAIDs but none of the stronger drugs.

- 2 - moderate $(n=41)$ : Patients who obtained NSAID combined with steroid or steroid alone.

- 3 - severe $(n=4)$ : Patients who obtained NSAID combined with steroid and immunosuppressant or who took only steroid in combination with immunosuppressant. We did not observe any patient who obtained only immunosuppressant drugs.

We emphasize here that the severity classification reflects the disease progression between January 1, 2010 and December 31, 2013 when drug obtainment records were available. In order to demonstrate the validity of the severity levels, we calculated the number of days (ND) the patients visited their physician or were treated in hospital with RP.

\section{Comorbidity networks}

We examined comorbidity patterns in the RP population $(n=233)$. We used ICD10 codes or groups of ICD10 codes to identify diseases in the HGFHD between January 1, 2002 and December 31, 2013. Besides providing tables 
with co-occurring disease pairs, we present our findings in a compact network form. ${ }^{31}$

The network representation has several advantages:

- Data are presented in a figure, where the placement (central, peripheral) and the distances between the objects (more connected ones are closer to each other than the less closely related objects) allow expression of qualitative information.

- Colors can be used to enhance similarity between groups of objects.

- Other graphical effects (eg, width of lines) help the readers to compare the intensity of relations between objects.

- The representation is more compact and visual, which allows finding hidden or nontrivial patterns with the human eye.

We present two different statistics for diseases appearing together in patients with confirmed RP diagnosis (population: $n=233$ ). The two versions correspond to two time ranges where we consider diseases to be co-occurring. For the first statistics, which we denote as lifetime comorbidity (LC), we considered all ICD10 codes that occurred during the whole time window of HGFHD and linked two diseases if they occurred in the same person without time restriction (Figure 1). This definition allowed us to observe possible long-term consequences or preliminary indicators. The other definition that we refer to as same day comorbidity (SDC) aims to shed light on closer connections between diagnoses by restricting the co-occurrence relation for the same person and for the same day (Figure 2). Note that if a patient had several visits on the same day at different places, observed diagnoses from all of the visits were considered to be co-occurring. Inpatient sessions were counted as their last-day event regardless of the length of the session. For reference, we provide the data in table form as well (Tables 2 and 3). We encourage the readers to take their own calculations by providing the data in excel format as downloadable Supplementary Table S2 as well.

\section{Results}

\section{Prevalence, incidence, mortality, and distribution by age and sex}

In Hungary, which is a Central European country with approximately ten million inhabitants, 256 patients were diagnosed with RP (ICD10 = M94.1) in the period from January 1, 2002 to December 31, 2013. In 233 cases, the diagnosis was confirmed by a clinician specialist, which corresponds to a 0.020 prevalence ratio per 1,000 of the cumulative insured patient pool in the 12-year-long time interval of the study ( $n=11.439$ million, where $\sim 100,000$ / year new patients were registered and $\sim 100,000$ /year patients exited from the system).

Figure 3 illustrates the incidence of RP in Hungary. For each year, we present the number of patients who were first

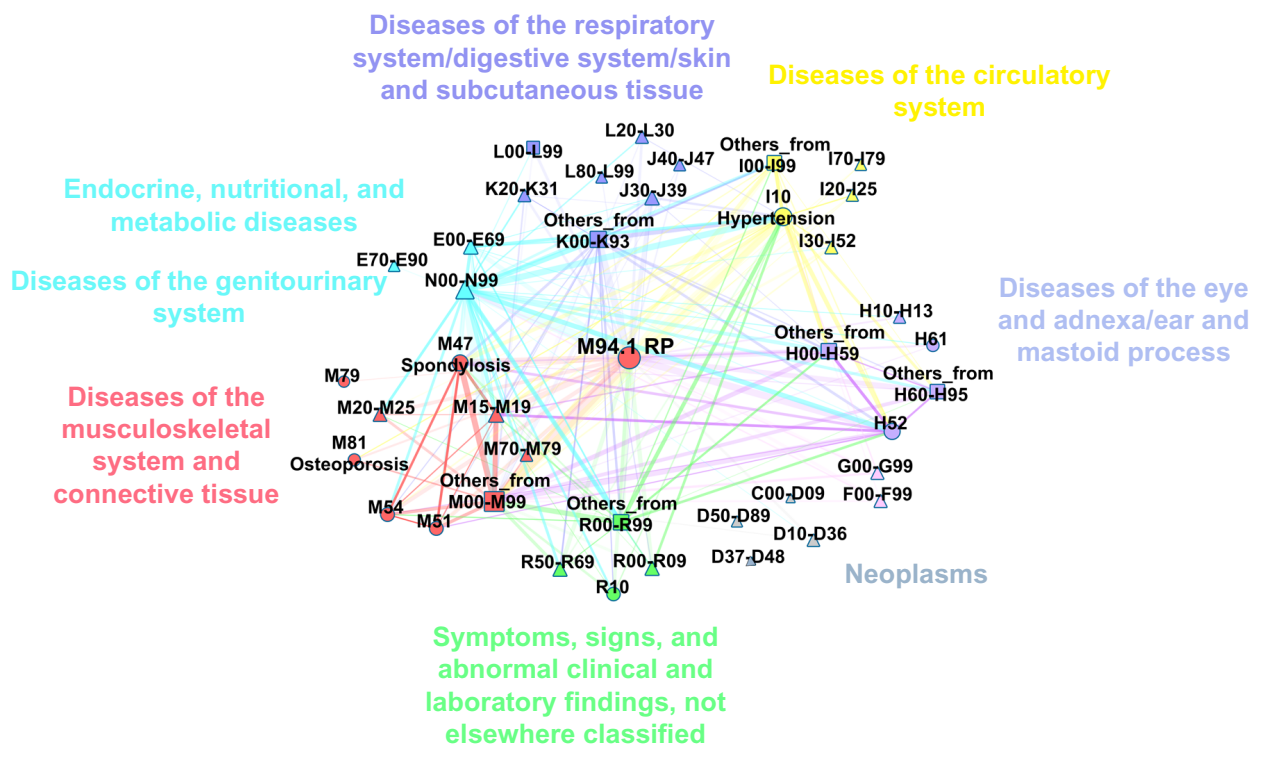

Figure I Network layout of most important lifetime comorbidities observed in Hungarian RP population.

Notes: Each point (node of the graph) represents a disease group indicated by labels. Points are connected with edges if diseases were diagnosed in the same patient between 2002 and 2013, regardless of time coincidence. The thickness of the edges indicates the number of affected patients, and transparency is higher for higher $P$-values. Only the most intensive, significant connections are represented. Note that RP is connected to each disease (this condition is part of the definition of the network), but these edges are very transparent. Size of the nodes is proportional to the number of patients affected in the disease group. Shape of the node indicates the type of the disease group: circle for three-character ICDIO code, triangle for ICDI0 section or merged consecutive sections, and squares for ICDIO chapters. Chapter groups labeled by "Others from" count cases with disease groups not represented separately, for example, "Others from M00-M99" does not include M94.I. This visual representation of comorbidities provides a map-like overview of possible long-term consequences or preliminary indicators of RP.

Abbreviations: RP, relapsing polychondritis; ICDI0, International Classification of Diseases I0th edition. 


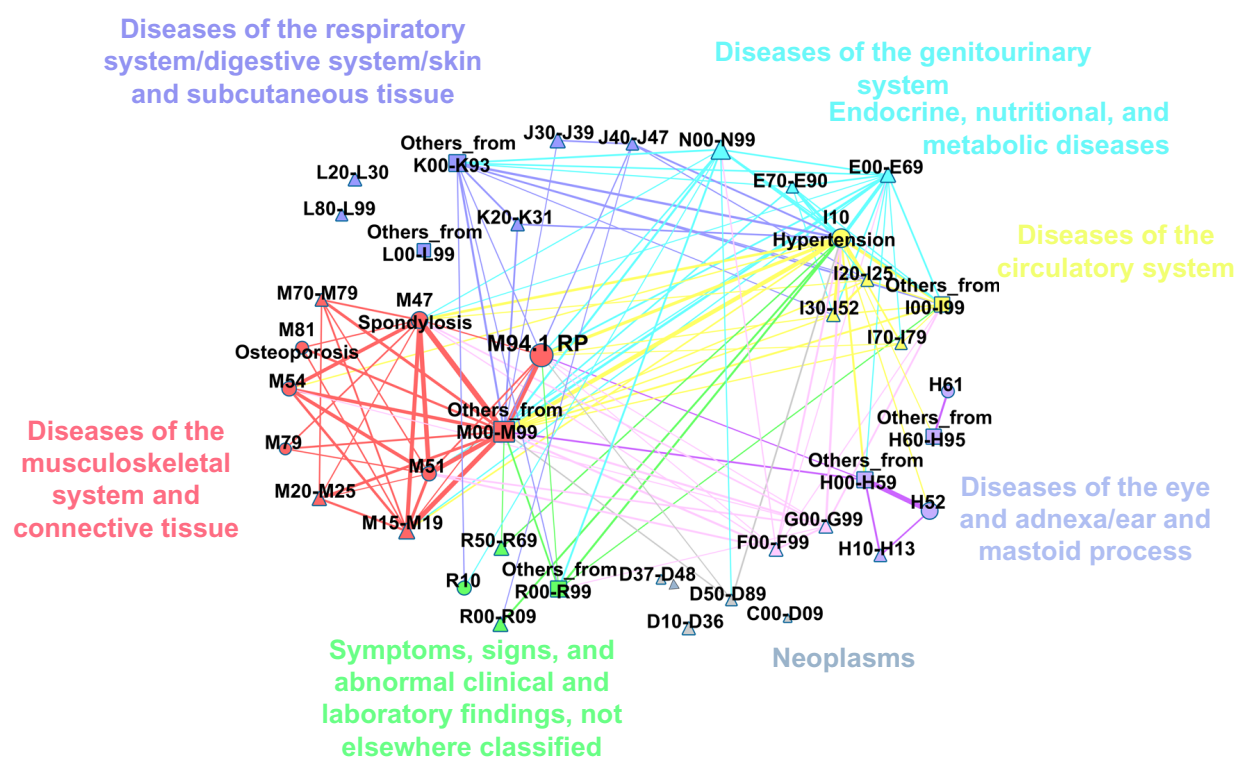

Figure 2 Same-day-comorbidity network of the Hungarian RP population.

Notes: The network and the layout definition is the same as for the lifetime comorbidity network, except that edges connect diseases if they occurred in the same person on the same day.

Abbreviation: RP, relapsing polychondritis.

diagnosed with M94.1 by a clinician specialist. Since we cannot distinguish the newly diagnosed patients from the chronic patients in the first year of HGFHD, we do not consider year 2002 here. Incidence data in Hungary are similar to the numbers reported elsewhere, for example, $3.5 / \mathrm{million} /$ year in Rochester (MN, USA). ${ }^{32}$

We calculated the overall survival (OS) for three different time lengths with the Kaplan-Meier formula, ${ }^{33}$ and the 95\% confidence intervals (CIs) were calculated according to the logarithmic transformation of Link. ${ }^{34}$ We provide the Hazard ratio analysis in the Supplementary material. The OS for 3 years was $93 \%$ (CI $=89.7-96.5)$, for 5 years was $88 \%$ $(\mathrm{CI}=83.6-92.9)$, and for 10 years was $81 \%(\mathrm{CI}=75.0-88.3)$.

In our pool, most of the patients with RP were middle aged. As Figure 4 shows, the ratio of patients who belonged to the $40-60$ age group was $43 \%$, although the age structure was rather shifted toward the older ages. The youngest patient was 4 years old, and the eldest was 93 years old. The sex ratios for all age groups show that females and males are affected equally by $\mathrm{RP}$ ( $P>0.05$ for each age group, $P=0.16$ for the total population). This is not typical of autoimmune diseases, since females are more affected by a large number of autoimmune diseases. ${ }^{35}$

\section{Levels of disease severity and hospitalization length}

We inferred the most severe status of RP in the period from 2010 to 2013 for the patients from drug consumption. From this analysis, we excluded individuals without confirmed
RP ( $n=23)$ and people without any record in the drug consumption database $(\mathrm{n}=22)$. In the rest of the population $(\mathrm{n}=211)$, the extremely mild condition was dominant $(68 \%)$, where no special drugs were applied. At higher progressed status (number of patients: $n=67$ ), drugs were involved in the treatment: NSAIDs, steroids, and immunosuppressant medicines. Immunosuppressants were used for the most severe cases $(n=4)$, steroids at the moderate level $(n=41)$, and NSAIDs for mild RP $(\mathrm{n}=22)$. Note that at higher levels, combinations of these drugs were used.

Figure 5 illustrates the drug consumption habits in mild, moderate, and severe patient groups. Most of the patients combined NSAIDs with steroids, and those who reached the highest level (taking immunosuppressants) had all been through some of the earlier stages. For each group, we provide basic epidemiological statistics in Table 1.

Table 1 presents the average and the standard deviations of ND for each group. Since the distribution of ND is highly skewed, we also included the first, second, and third quartile values. The length of hospitalization shows an increasing tendency as the disease progresses to more severe forms (Figure 6). There are outliers in each group due to complicated comorbidities (higher ND) or very effective drug treatments (lower ND).

\section{Typical diseases occurring with RP}

In patients with RP, several kinds of diseases appeared, mainly on a different day than when RP was diagnosed. We describe here the most frequent diseases (ICD10 codes are provided 


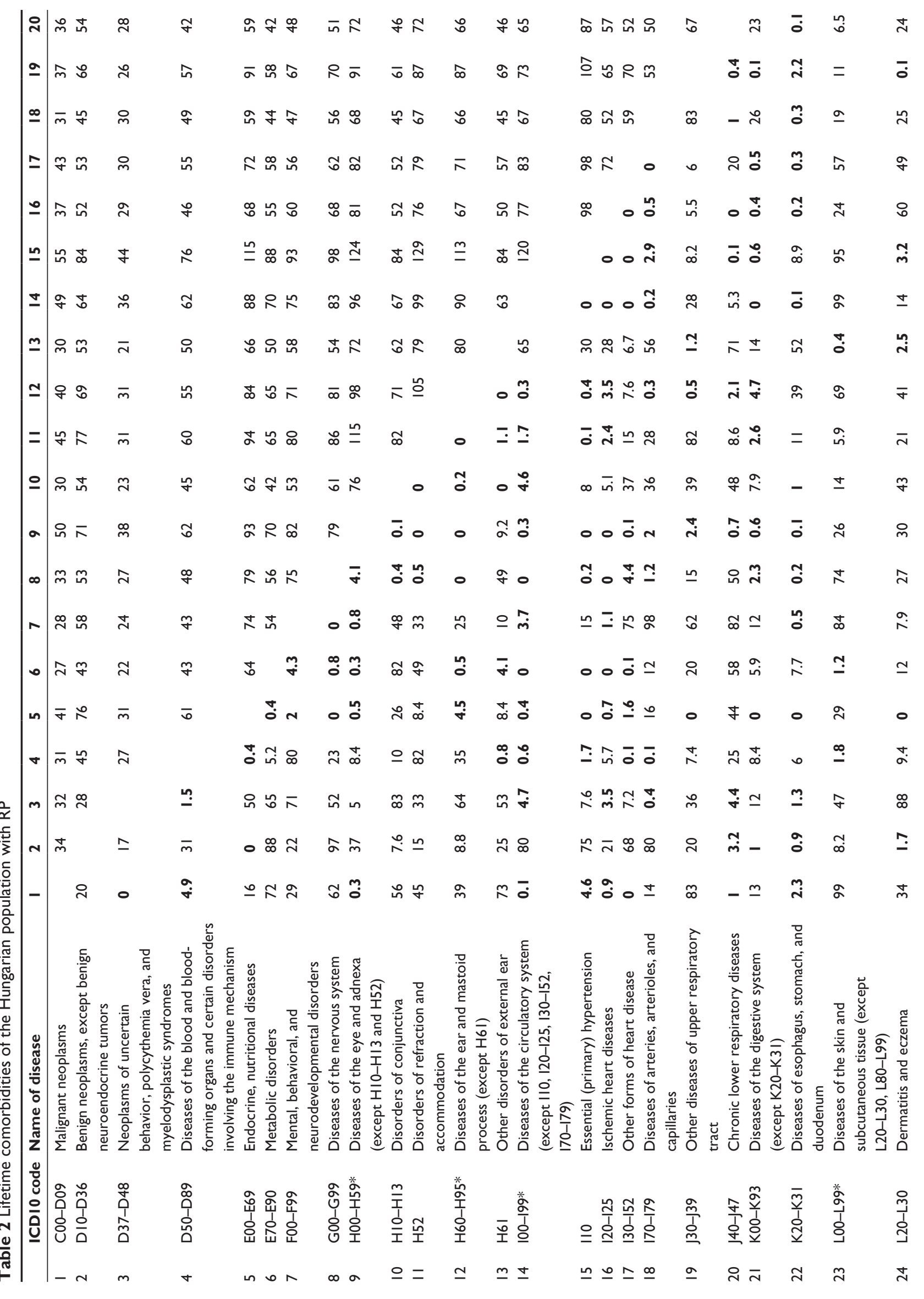




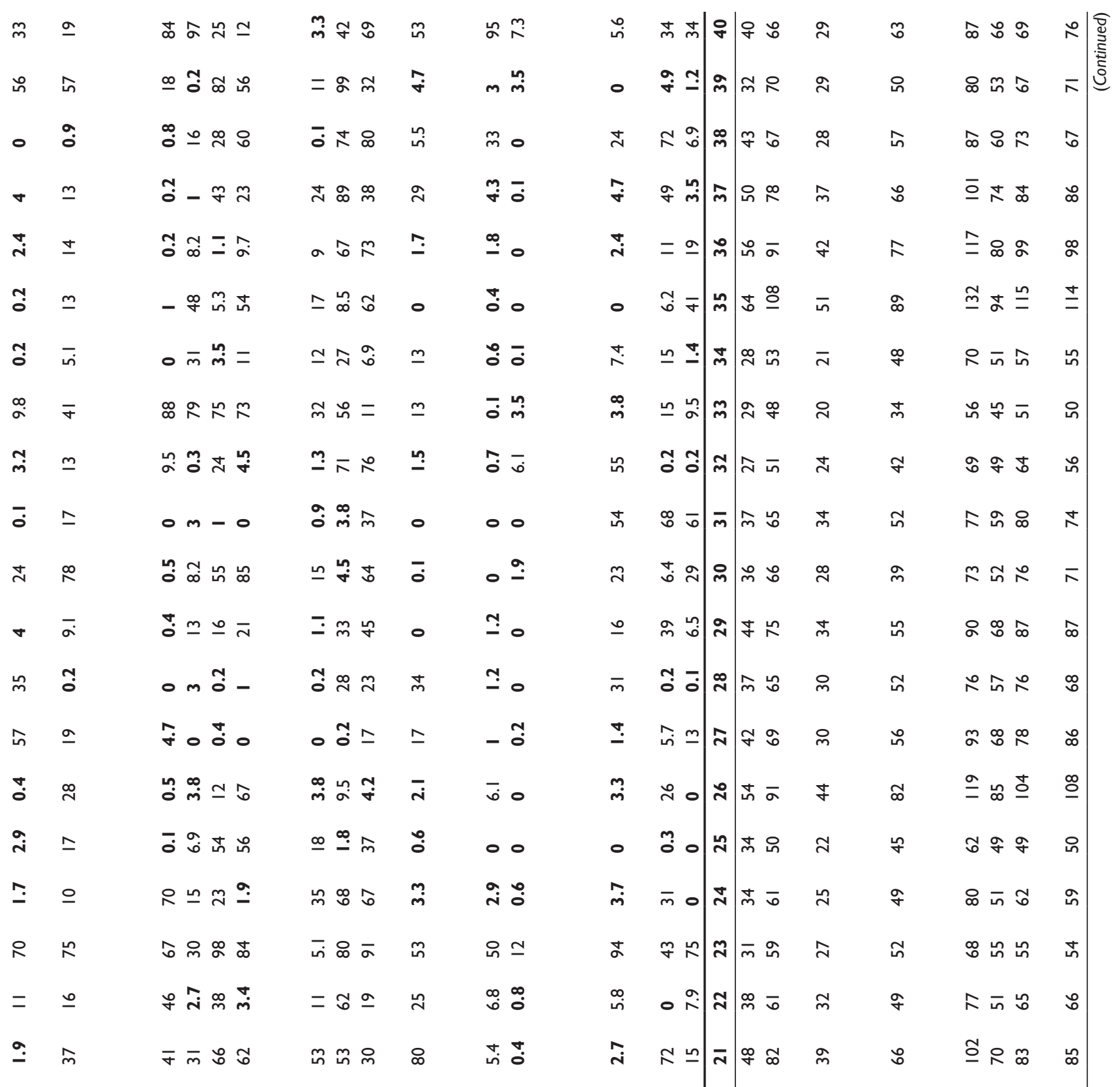

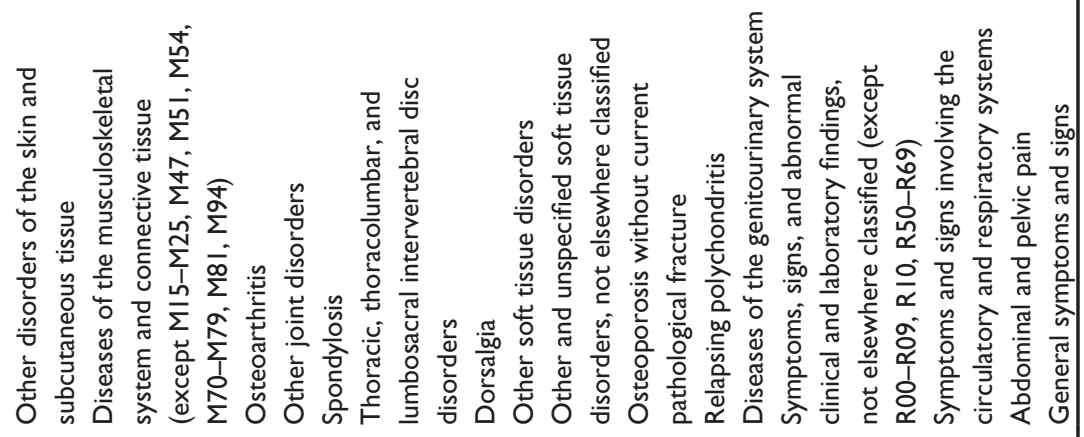

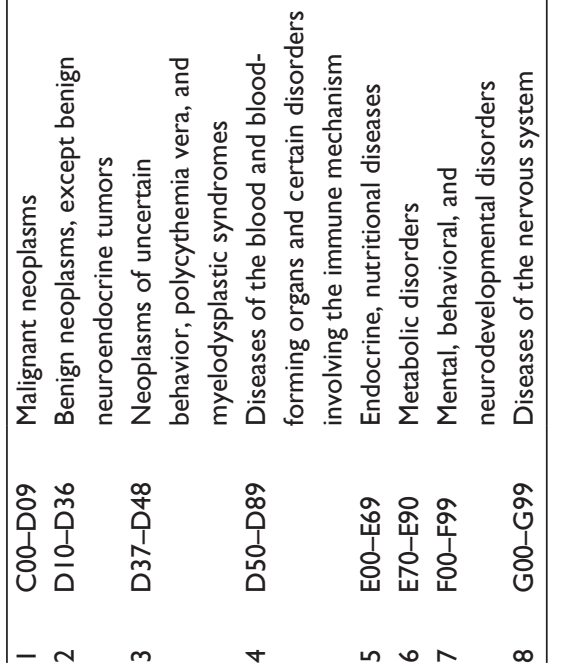




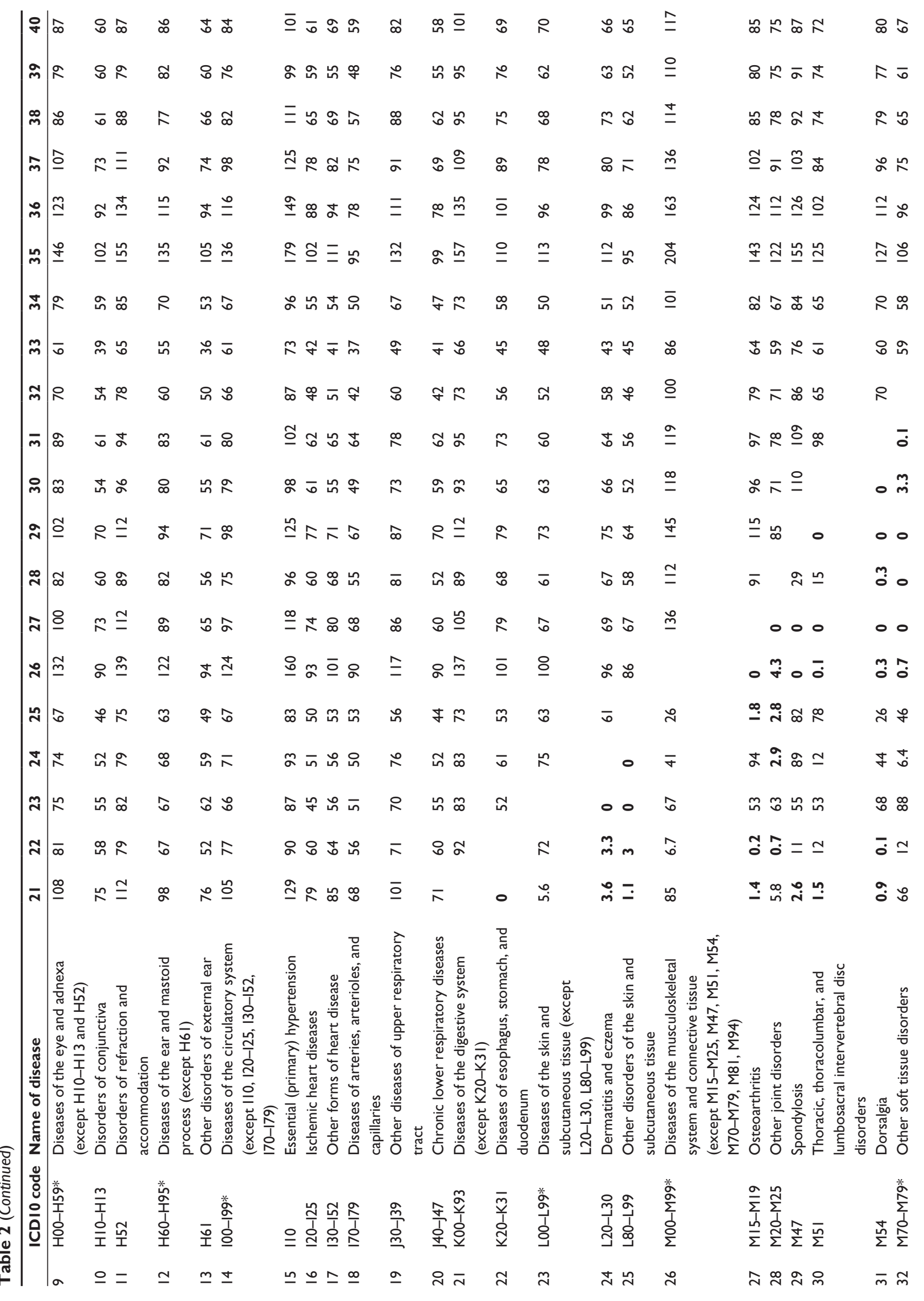




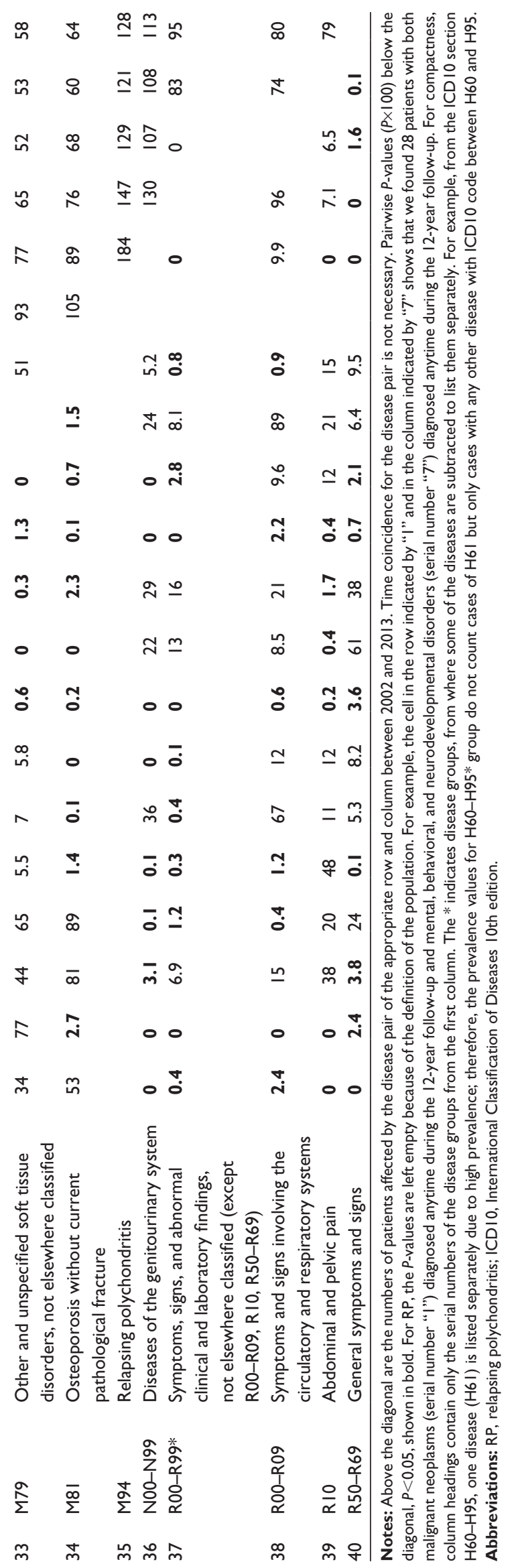

in Table S1 for the named diseases). For each disease, we list two proportions of the patients with RP. The first number represents the relative frequency of the LC in the RP population, and the second percentage indicates the SDC. Both proportions result from the fraction where the numerator is the number of individuals diagnosed with the disease in question and the denominator is the population size of persons with confirmed RP ( $n=233)$.

The five most common LCs were hypertonia ( $\mathrm{LC}=77 \%$, $\mathrm{SDC}=25 \%$ ), spondylosis $(\mathrm{LC}=67 \%, \mathrm{SDC}=12 \%)$, disorders of refraction and accommodation ( $\mathrm{LC}=67 \%, \mathrm{SDC}=5 \%$ ), back pain $(\mathrm{LC}=55 \%, \mathrm{SDC}=7 \%$ ), and other intervertebral disc disorders ( $\mathrm{LC}=54 \%, \mathrm{SDC}=15 \%)$. Among patients with $\mathrm{RP}$, thyroid dysfunction ( $\mathrm{LC}=25 \%, \mathrm{SDC}=4 \%$ ) and type 2 diabetes ( $\mathrm{LC}=16 \%, \mathrm{SDC}=5 \%$ ) were detected. More than a quarter of the patients ( $\mathrm{LC}=27 \%, \mathrm{SDC}=4 \%$ ) were diagnosed with some kind of malignant cancer (lung, skin, breast, or colorectal cancer) in the examined time range. In Hungary, $56 \%$ of patients with RP were registered with another autoimmune disease at least once in the HGFHD. Most often, persons were affected by Sjögren syndrome ( $\mathrm{LC}=26 \%, \mathrm{SDC}=12 \%$ ), rheumatoid arthritis ( $\mathrm{RA})(\mathrm{LC}=20 \%, \mathrm{SDC}=5 \%$ ), and systemic lupus erythematosis ( $\mathrm{LC}=6 \%, \mathrm{SDC}=3 \%$ ). Some of the autoimmune diseases were diagnosed typically by different specialists; therefore, the LC and SDC ratios were very different. The three most frequent diseases of this type were thyrotoxicosis ( $\mathrm{LC}=9 \%$, SDC $=2 \%)$, iridocyclitis $(\mathrm{LC}=9 \%$, SDC $<1 \%)$, and psoriasis $(\mathrm{LC}=6 \%, \mathrm{SDC}<1 \%$ ).

Respiratory infections like sinusitis, rhinitis, bronchitis, influenza, and pneumonia were also very common during the lifetime of the patients ( $\mathrm{LC}=48 \%, \mathrm{SDC}=3 \%$ ). However, SDC was relatively low indicating a weak connection with RP. A similar contrast was observed for common infectious conjunctivitis ( $\mathrm{LC}=37 \%, \mathrm{SDC}=4 \%$ ). More than $30 \%$ of the patients were registered in HGFHD with at least one of the following conditions: coxarthrosis, dermatitis, ischemic heart disease, lipoprotein disorders, depression, and anxiety problems.

In order to shed light on the interplay between the cooccurring diseases, ${ }^{36}$ we constructed the LC network and the SDC network. In these networks, diseases are represented by points (nodes). Point pairs are connected if there is at least one person affected by both diseases. The links between the nodes are weighted with the number of patients who were diagnosed with the disease pair. In the visual representations of these networks in Figures 1 and 2, we show only links with the largest weights and where the co-occurrence rate is significantly ( $95 \% \mathrm{CI}$ ) higher than it would be, assuming independent random coincidence. We did not include in the 


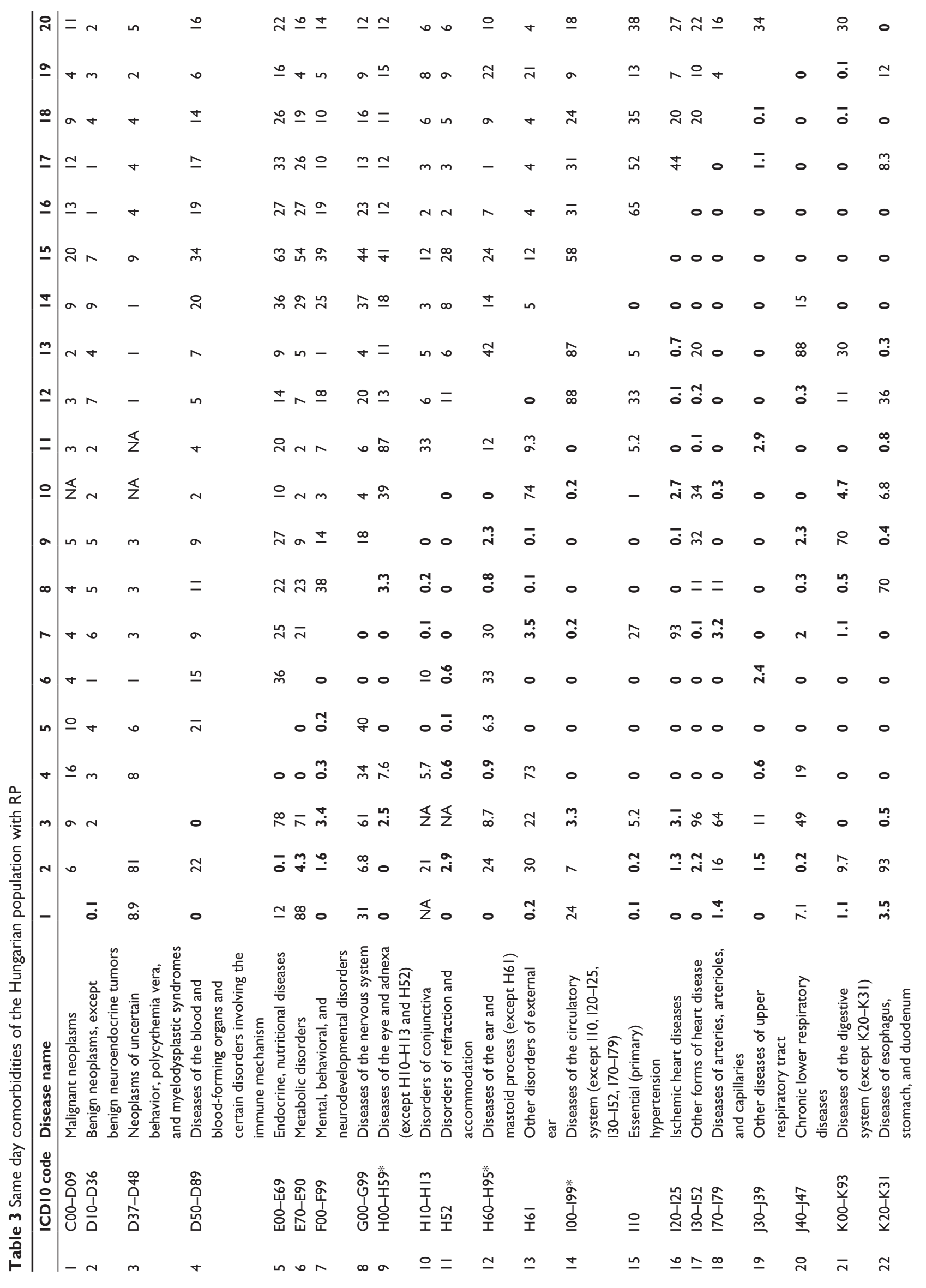




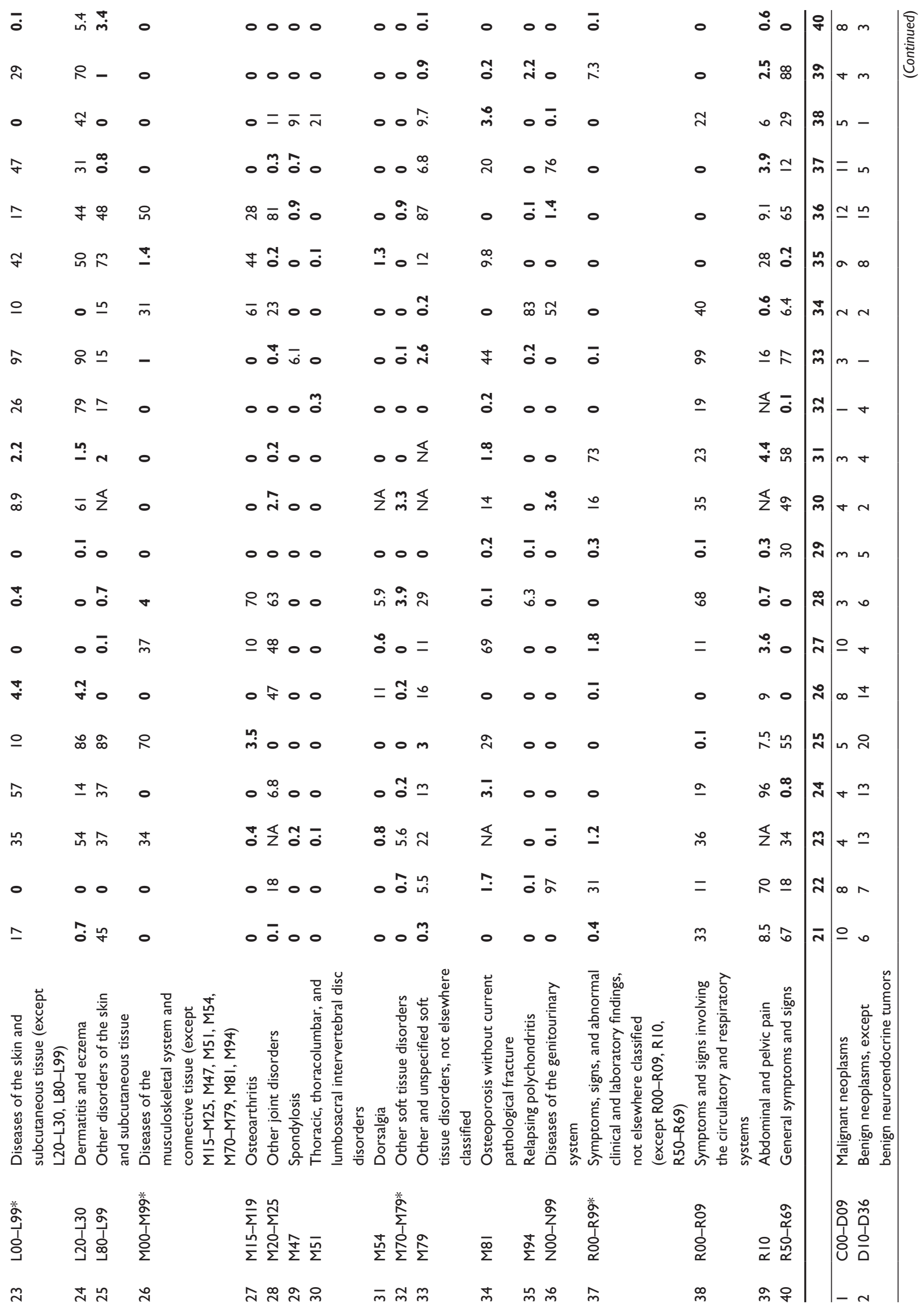




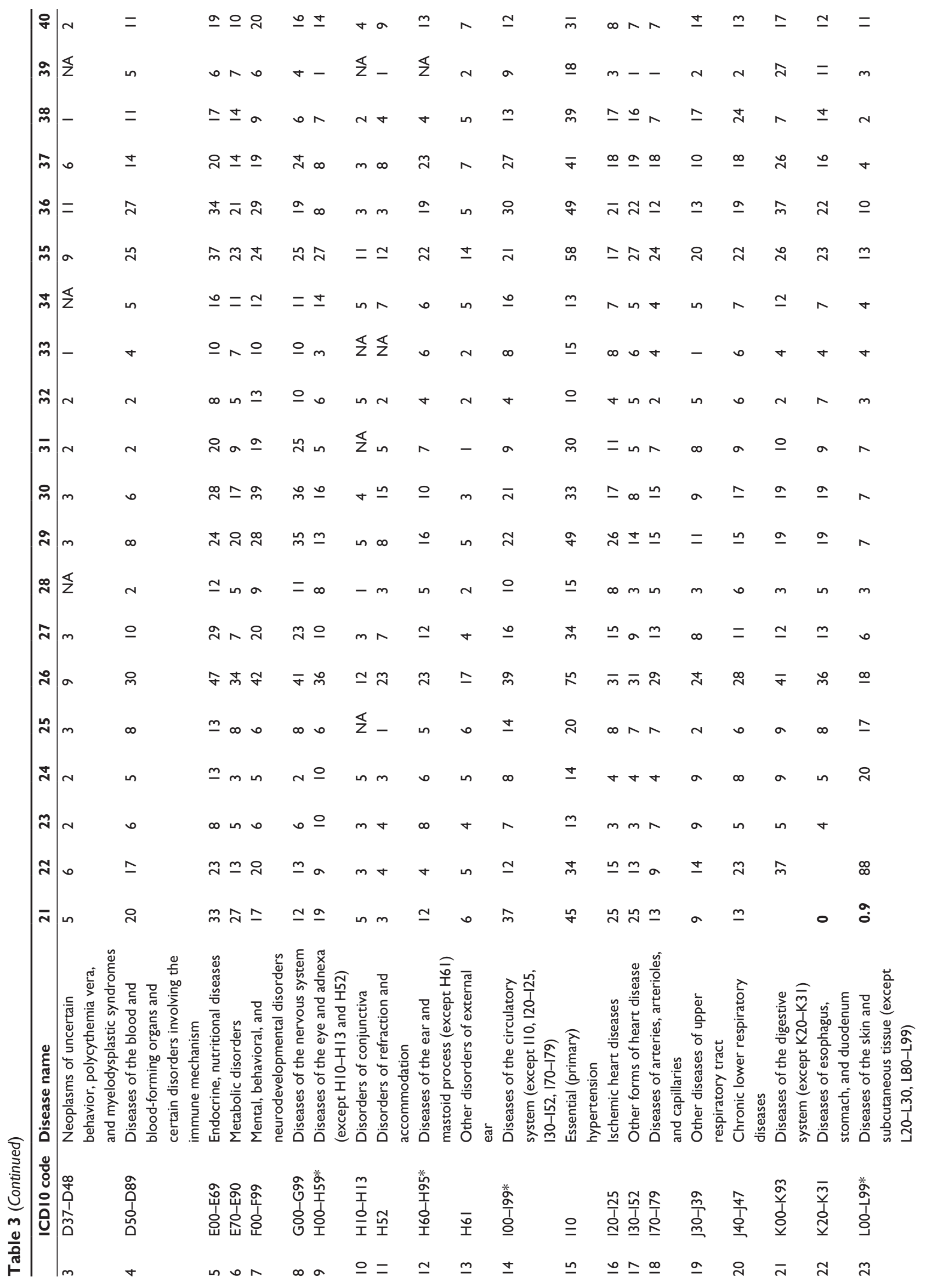




\begin{tabular}{|c|c|c|c|c|c|c|c|c|c|}
\hline$\infty \infty$ & $\stackrel{\sim}{\sim}$ & $\underline{m}$ in $\simeq$ 으 & n -- & $N$ & $\underline{\sim} \bar{N}$ & $\underline{\infty}$ & $\infty$ & $\wedge$ & 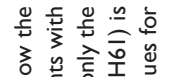 \\
\hline$-n$ & $a$ & $4 N \sin \theta$ & $4 n 4$ & - & $+\stackrel{4}{N}$ & $\infty$ & $\nabla$ & $\stackrel{\varphi}{\forall}$ & 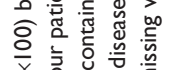 \\
\hline$n n$ & $\underline{\alpha}$ & $n n=\infty$ & 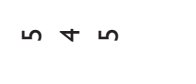 & in & $=0$ & $\stackrel{\llcorner}{+}$ & & $œ \simeq$ & 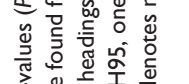 \\
\hline$\circ \mathrm{m}$ & $\stackrel{\circ}{m}$ & $\underline{n} \wedge \bar{N} \simeq$ & or n & 으 & 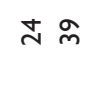 & & 으 & స 0 & 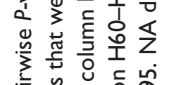 \\
\hline \pm & F & 느 으 웃유 & $\bar{N} \sigma r$ & $\underline{\underline{n}}$ & $\tilde{m}$ & 0 & $\pi$ & $\circ \stackrel{\sigma}{\sigma}$ & 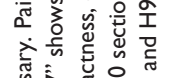 \\
\hline$\pm \underline{m}$ & $a$ & 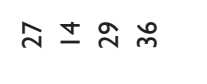 & $\simeq \underline{m}$ & 요 & $\stackrel{\sim}{*}$ & 0 & $\stackrel{m}{-}$ & $\stackrel{0}{0} 0$ & 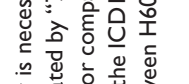 \\
\hline-+ & f & లై & $\underline{0}=\infty$ & & లి & $\simeq$ & $\bar{N}$ & $\bar{m} \stackrel{n}{\mathbf{i}}$ & 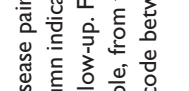 \\
\hline$n N$ & $\stackrel{\infty}{m}$ & $\bar{\sim} \simeq \dot{m} \vec{\sim}$ & $\stackrel{\sim}{\sim} \stackrel{\infty}{-}$ & 0 & 00 & $r$ & Ұ & $\underline{ㄴ ㅡ}$ & 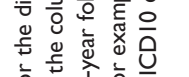 \\
\hline$\overleftarrow{z}+$ & ثे & $\stackrel{\infty}{\infty} \approx \tilde{m}^{\infty} \bar{m} \bar{m}$ & $\approx 0$ & 0 & ì & T̃ & $\stackrel{\circ}{-}$ & $-\overline{0}$ & 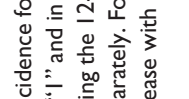 \\
\hline N- & T & q $\approx$ 号 & 00 & $\stackrel{\infty}{\sim}$ & 00 & 0 & $\circ$ & $\overline{0} 0$ & 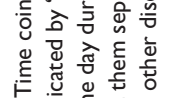 \\
\hline in 0 & $\stackrel{2}{r}$ & ํํํ 눙 & 000 & 0 & $m_{m}^{m} 0$ & 0 & 0 & 00 & 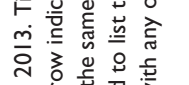 \\
\hline$m n$ & ஃ & $N \stackrel{\infty}{\sim} \quad 0$ & 000 & ○ & $\stackrel{m}{*} 0$ & กุ & 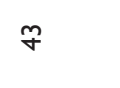 & $0=$ & 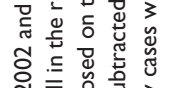 \\
\hline$\S \leftleftarrows$ & กี & $\dot{y} \quad \hat{i} 0$ & 000 & 0 & $\infty$ & $\stackrel{0}{-}$ & $\underline{n}$ & $\stackrel{m}{\rightarrow} \stackrel{0}{0}$ & 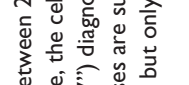 \\
\hline$+m$ & 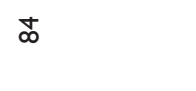 & 000 & $00 \bar{m}$ & 0 & 00 & 0 & 0 & $-\stackrel{\infty}{m}$ & 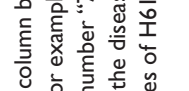 \\
\hline$\simeq \simeq$ & & 0000 & 000 & 0 & 00 & $\ddot{\sim}$ & 0 & $\circ 5$ & 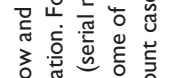 \\
\hline ำ & 0 & 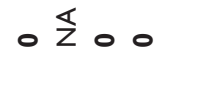 & 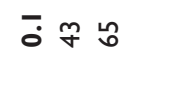 & $\tilde{m}$ & $\hat{\sim} \stackrel{m}{-}$ & $\underline{m}$ & $\stackrel{\sim}{\sim}$ & m̃o & 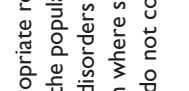 \\
\hline 0 & 0 & $0 \mathbb{Z} 00$ & o $\mathbb{Z} \stackrel{0}{m}$ & $\stackrel{\infty}{0}$ & $\bar{N} 0$ & $\hat{\sigma}$ & 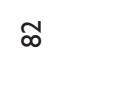 & $=\pi$ & 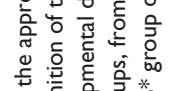 \\
\hline 00 & 0 & 0 ○ั 00 & $00 \bar{F}$ & $\stackrel{m}{0}$ & $\stackrel{n}{-} 0$ & $\stackrel{\infty}{-}$ & $\underline{\underline{n}}$ & $\dot{m} \stackrel{m}{0}$ & 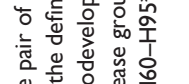 \\
\hline$\alpha R$ & 0 & Rfoo & $\simeq \simeq \simeq$ & 0 & $0=$ & 0 & 0 & : & 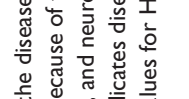 \\
\hline సి $\infty$ & 0 & กี่ 000 & $00 \stackrel{m}{0}$ & 8 & OR & $\circ$ & $\simeq$ & $0 \stackrel{0}{0}$ & 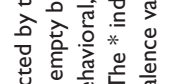 \\
\hline 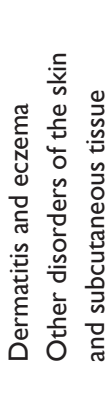 & 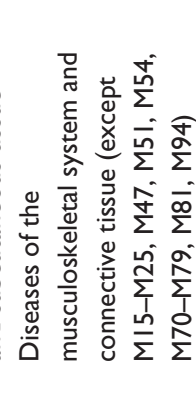 & 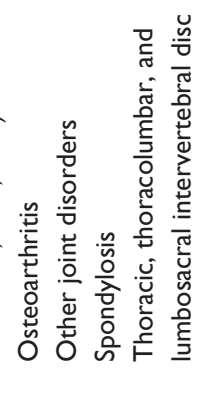 & 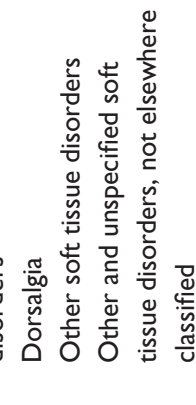 & 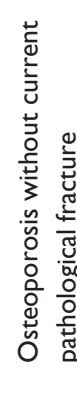 & 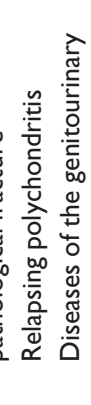 & 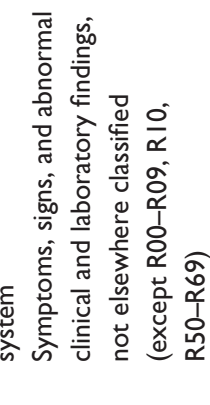 & 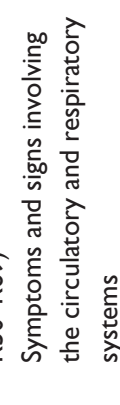 & 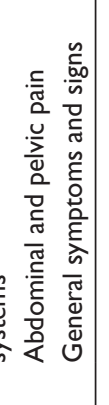 & 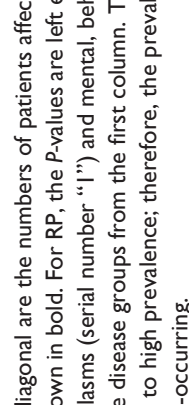 \\
\hline 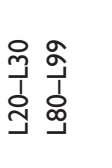 & $\begin{array}{l}\text { * } \\
\sum_{0}^{\circ} \\
\text { O } \\
\Sigma\end{array}$ & 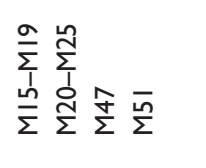 & 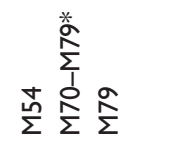 & $\stackrel{\bar{\infty}}{\Sigma}$ & 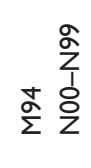 & 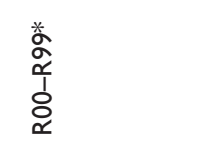 & 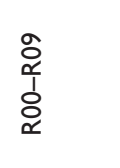 & 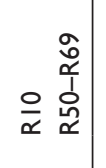 & 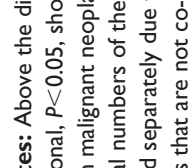 \\
\hline 岇峑 & స & స & $\bar{m} \tilde{m} \tilde{m}$ & "̈ & $\stackrel{m}{m}$ & $\hat{m}$ & $\stackrel{\infty}{m}$ & के q o & \\
\hline
\end{tabular}




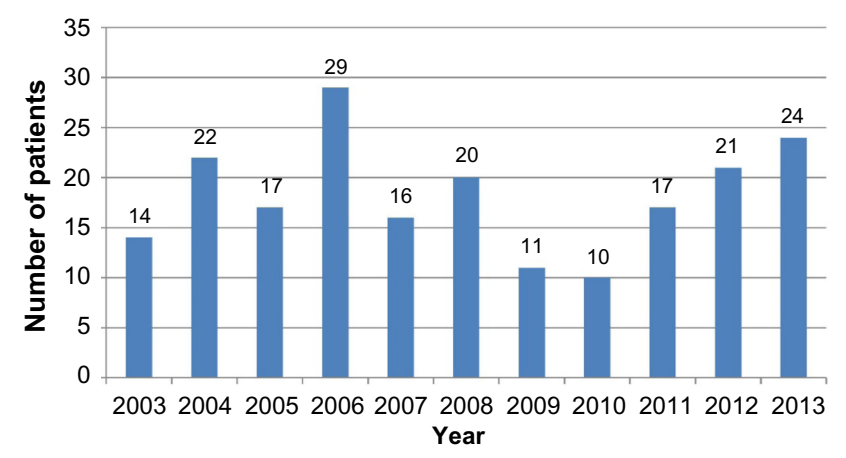

Figure 3 Number of newly diagnosed patients for each year during the examined period.

Abbreviation: RP, relapsing polychondritis.

network incidental diseases that are listed with ICD10 codes from chapters "Certain infectious and parasitic diseases" and "Injury, poisoning and certain other consequences of external causes". Detailed co-occurrence statistics are given in Tables 2 and 3. We advise the readers to look at the networks as a large scale map of the landscape of co-occurring diseases, while for interesting details, they can refer to the tables which present exact numbers. Further analysis is possible with the electronic Supplementary Table 2 and S3.

\section{Discussion}

The retrospective analysis with the Hungarian Health Care Database is inevitably tied to the coding system of the International Classification of Diseases. Though the diagnoses are those recorded by treating physicians in the routine practice of care, incidental misdiagnoses or errors in the coding pro- cedure may influence the results. Another possible reason for underestimating the incidence and prevalence is that the HGFHD does not register visits in primary care and visits without any public financial support. We expect that the very low number of private clinics perform a negligible portion of treatments. We also expect that patients with sound manifestations of RP are likely to come to the attention of specialists even if care is initially provided by a primary care practitioner.

Based on the medical profession of the treating divisions, we identified 23 patients out of 256 who were registered with $\mathrm{RP}$, where the diagnosis was probably only a suspicion. This indicates a $10 \%$ false-positive error in the Hungarian registerbased prevalence. However, this estimated error rate is not necessarily applicable for other diseases. Frequent symptoms are probably registered more reliably. Indeed, other factors are known to cause errors in public health care databases, for example, administrative rules induce an overestimation of hypertension. The detailed analysis of data accuracy in registers needs deep knowledge of each disease and the ICD10 coding algorithms in individual institutes. In the co-occurrence analysis, we did not carry out accurate analysis of other diseases, and prevalence numbers were reported without any corrections. The estimation of false-positive error and false-negative error could be improved by medical chart review of the population. Even better results would be possible by visiting each patient. Here, we have used only the Hungarian Health Care Database. The strong association with RA can induce further classification bias, where RP is identified as RA or vice versa.

The incidence and prevalence of RP in Hungary is consistent with earlier international findings: it affects males

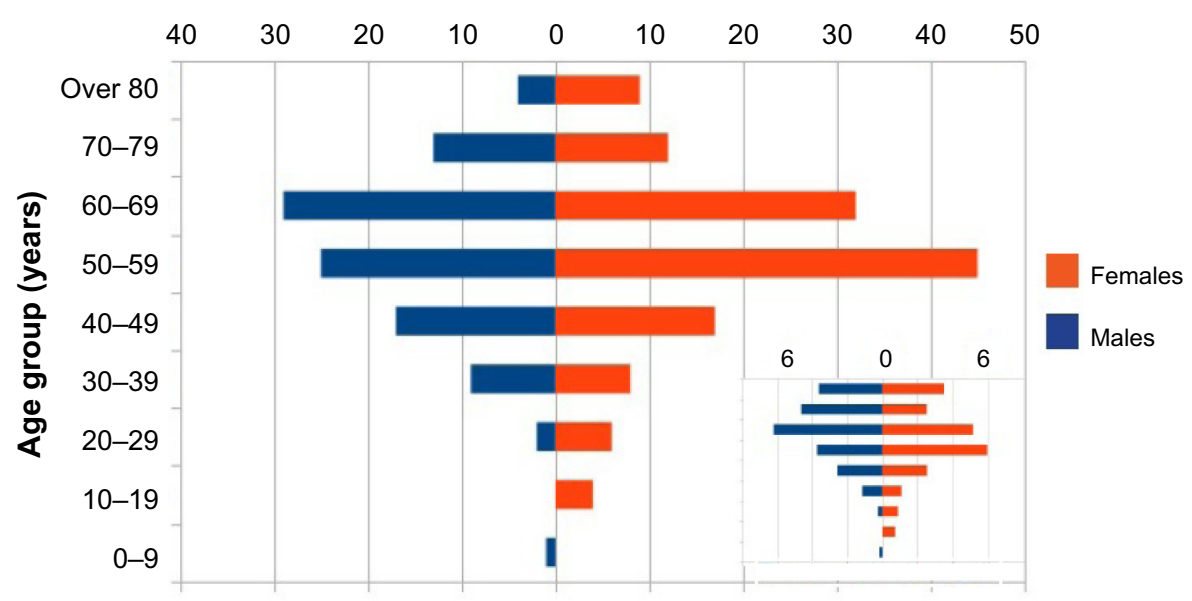

Number of patients

Figure 4 Age structure diagram of patients diagnosed with ICDI0 M94.I.

Notes: Both sexes are affected equally. RP appears most likely in the population aged 40-60 years. The inset shows the standardized age structure. Abbreviations: RP, relapsing polychondritis; ICDI0, International Classification of Diseases 10th edition. 


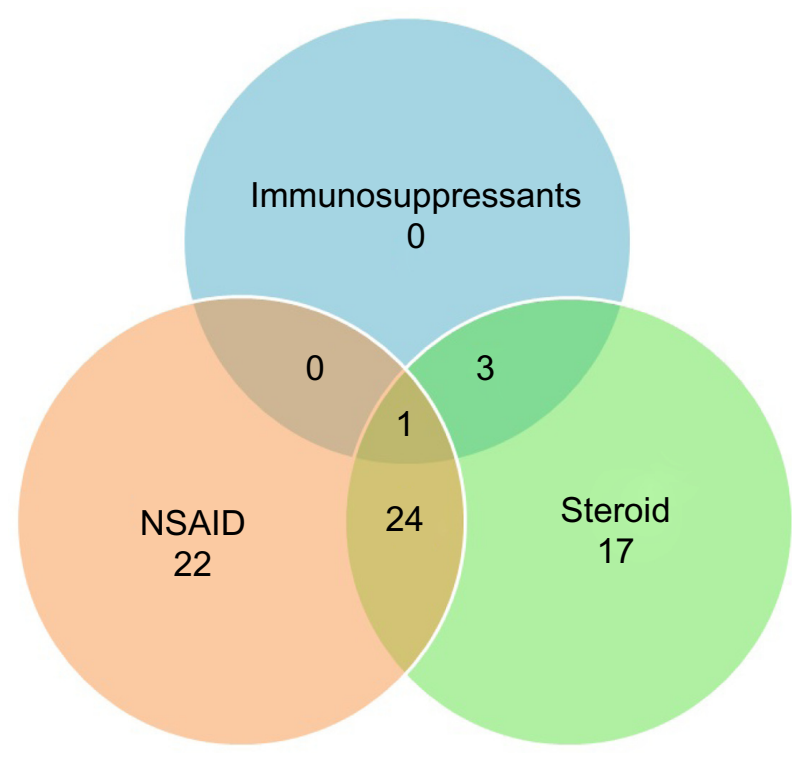

Figure 5 Distribution of number of patients according to drug consumption. Abbreviation: NSAID, nonsteroid anti-inflammatory drug.

and females equally, and it can appear any time from early childhood until the end of late adulthood. The most affected age group is the middle-aged population. The simple overall mortality ratio of RP in Hungary was $12.9 \%$ as 30 patients died during the 12-year-long examination period. The exact cause of death is not always recorded in the HGFHD. There- fore, we do not have any reliable data about 16 cases of deaths. In 14 cases where data are available, RP was not registered as the cause of death. However, from the last premortem 30-day records, we raise the possibility that in two cases, fulminant RP could be the reason of loss of life. In one of these cases, unspecified contracted kidney was observed, and in the other case, acute respiratory failure was the last diagnosis. The survival rates in Hungary are significantly better than the worldwide rates reported by Michet et al. ${ }^{4}$ The 5 -year survival rate was reported to be $66 \%-74 \%$ ( $45 \%$ with co-occurring systemic vasculitis), which is below the lower confidence limit of $83.6 \%$ inferred from Hungarian data. The 10 -year survival rate was $55 \%$ around the globe, which is less than the lower confidence limit of $75 \%$ in Hungary. The good Hungarian survival values can be related with the severity distribution, where only four cases out of 211 were in severe state and 144 cases in the extremely mild (no reason for applying any special drugs) state. Note that the OS rates of RP correspond to the rates for the general Hungarian population ( 5 -year OS $=89 \%, 10$-year OS $=79 \%$ ).

Among patients with RP in Hungary, the most common comorbidity is hypertonia, which is probably the consequence of the age distribution of the RP population. The second comorbidity is spondylosis surely associated with RP. It can warn a physician in practice about the activation of RP. More than half of the patients with RP have another concurrent

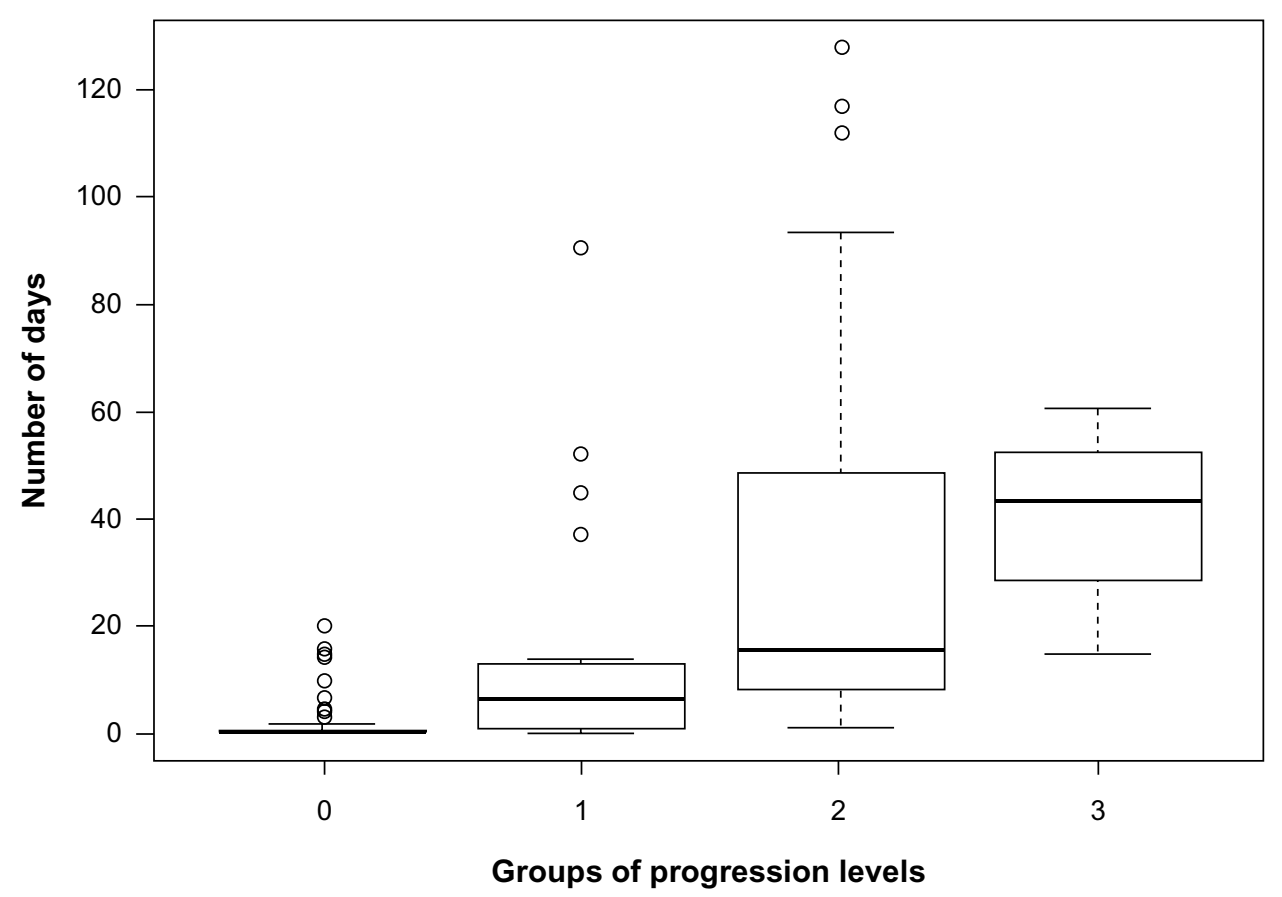

Figure 6 Box plot for number of days of hospitalization versus disease progression levels.

Notes: The progression level was identified from drug consumption patterns. Number of days increases as the disease progresses to more severe levels. 


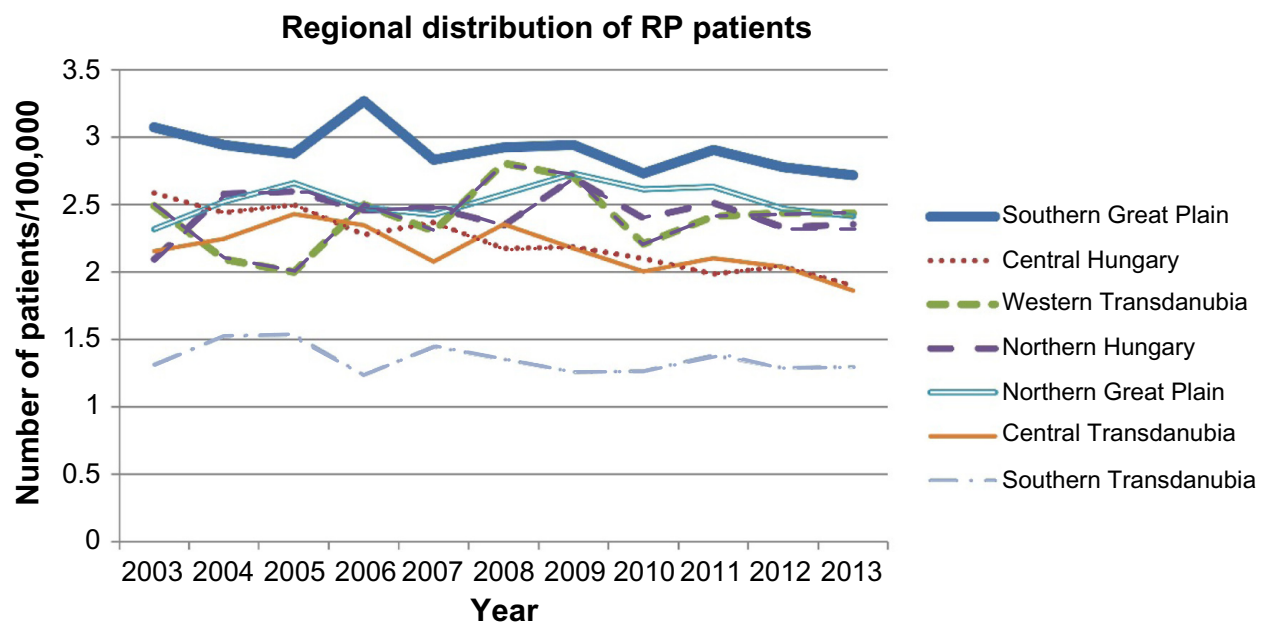

Figure 7 Regional distribution of incidence ratios.

Note: The high difference between the two neighboring southern regions (Southern Great Plain and Southern Transdanubia) hints for possible environmental triggering effects.

Abbreviation: RP, relapsing polychondritis.

autoimmune disease. This comorbidity ratio is higher than the earlier reported $25 \%-35 \%{ }^{3}{ }^{3,16}$ We suspect that this difference may be related to the low mortality rate in the Hungarian cohort, which allows time for other autoimmune diseases to develop in affected patients. According to the marked variability of manifestations of RP, several other comorbidities were diagnosed in the time interval of the study. Diseases of the musculoskeletal system and connective tissue dominate the comorbidity networks, though diseases of the eye and adnexa, diseases of the circulatory system, and diseases of the respiratory system are characteristic groups as well, besides endocrine, nutritional, and metabolic diseases. Malignant cancer in more than a quarter of the RP population indicates a disorder in the immune system; all kinds of cancers can appear with RP. Because of the observed high rate of osteoporosis, we recommend osteodensitometry screening before RP therapy. We have not seen any significant connection with pregnancy, childbirth, and the puerperium. The low co-occurrence with congenital malformations, deformations, and chromosomal abnormalities is also worth noting.

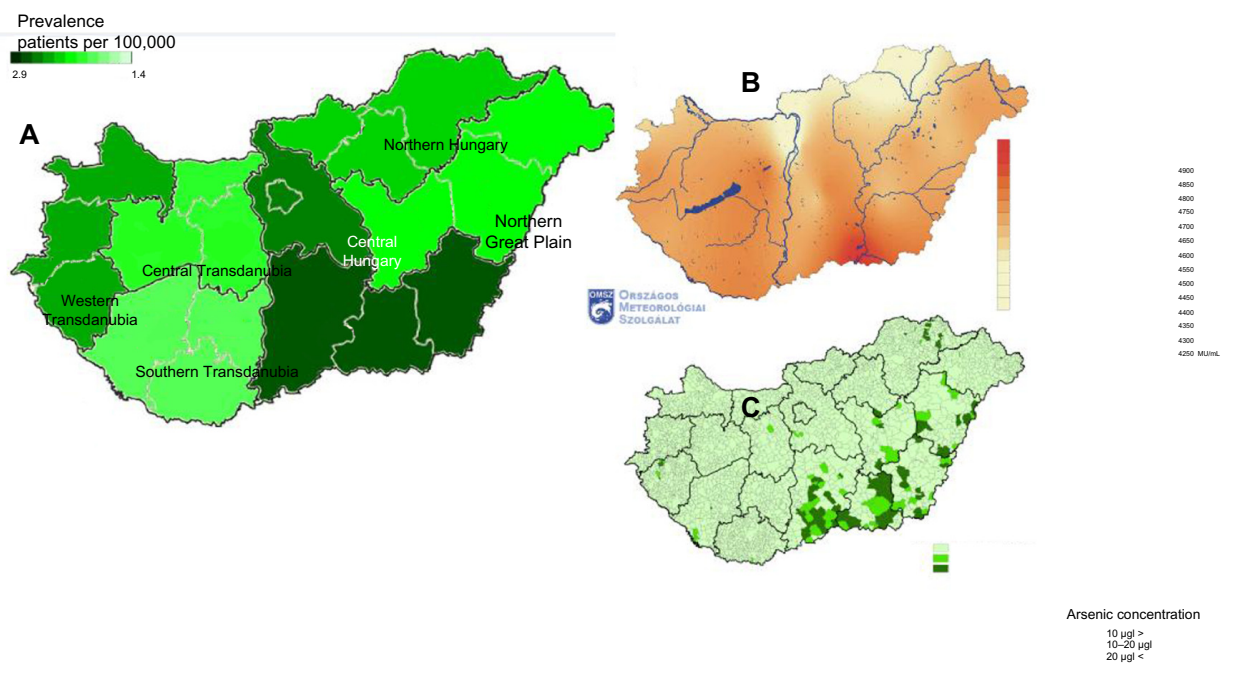

Figure 8 Residence of patients with RP.

Notes: (A) the prevalence region is located by the place of residence of the patient. (B) shows the sunlight exposure and (C) the arsenic content of drinking water. B is reproduced with permission from the Hungarian Meteorological Service (HMS). Hungary sunlight, sunshine duration and cloud cover conditions. Available from: http://met. hu/eghajlat/magyarorszag_eghajlata/altalanos_eghajlati_jellemz es/sugarzas/. ${ }^{37} \mathrm{C}$ is reproduced with permission from National Public Health Service. [Drinking Water Quality, 2012] Ivóvíz minöség, 20I2. Available from: https://www.antsz.hu/data/cms52I I 5//vovizminoseg_20I2_honlapra_20I40404.pdf. ${ }^{38}$

Abbreviation: RP, relapsing polychondritis. 
We identified treatment patterns from drug consumption data, and we classified patients into severity classes accordingly. The number of visiting days (indicated by ND) seems to be on average higher for more severe cases. Indeed, we cannot determine the effectiveness of the therapies. The available short time interval of drug usage does not allow us to study long-term differences between NSAID, steroid, or immunosuppressant therapies. However, some patients $(\mathrm{n}=20)$ with earlier frequent hospital admissions (number of records with RP in HGFHD is higher than ten) were not diagnosed later on, indicating some successful therapies, but in these cases, drug usage data are not available for the time interval of the earlier frequent visits. Hence, these patients are included in the extremely mild class.

We close our discussion with an open question on the possible triggering effects of RP. Figures 7 and 8 present the standardized regional distribution of patients with RP in Hungary. The highest morbidity rate is observed in the Southern Great Plain region, where effects from ultraviolet sunshine and toxic agents in drinking water are higher than in other regions. This geographical coincidence hints for possible environmental triggers of RP as higher arsenic component ${ }^{39}$ in drinking water and intensive sunlight exposure.

\section{Conclusion}

We present for the first time a nationwide epidemiology of RP with detailed comorbidity statistics. In Hungary, the survival rate is good, and most of the RP cases are diagnosed in less severe stage. The presented data can help to better understand this complex disease and improve the worldwide survival rate of patients with RP.

\section{Acknowledgments}

This research was partially supported by the European Union and the European Social Fund through project FuturICT.hu (grant no. TAMOP-4.2.2.C-11/1/KONV-2012-0013), by the EU FP7 ERC COLLMOT project (grant no. 227878), and by the Hungarian National Science Fund (OTKA K105447). The funders had no role in study design, data collection and analysis, decision to publish, or preparation of the manuscript.

\section{Disclosure}

The authors report no conflicts of interest in this work.

\section{References}

1. Lahmer T, Treiber M, von Werder A, et al. Relapsing polychondritis: an autoimmune disease with many faces. Autoimmunity Reviews. 2010;9(8):540-546.

2. Cantarini L, Vitale A, Brizi MG, et al. Diagnosis and classification of relapsing polychondritis. Journal of Autoimmunity. 2014;48-49: 53-59.
3. McAdam LP, O'Hanlan MA, Bluestone R, Pearson CM. Relapsing polychondritis: prospective study of 23 patients and a review of the literature. Medicine. 1976;55(3):193-215.

4. Michet CJ Jr, McKenna CH, Luthra HS, O'Fallon WM. Relapsing polychondritis. Survival and predictive role of early disease manifestations. Annals of Internal Medicine. 1986;104(1):74-78.

5. Michet CJ. Etiology and pathogenesis of relapsing polychondritis. 2013. Available from: http://www.uptodate.com/contents/etiologyand-pathogenesis-of-relapsing-polychondritis. Accessed on April 15, 2016.

6. Drosos AA. Relapsing polychondritis. 2004. Available from: https:// www.orpha.net/data/patho/GB/uk-RP.pdf. Accessed on April 15, 2016.

7. Trentham DE, Le CH. Relapsing polychondritis. Annals of Internal Medicine. 1998;129(2):114-122.

8. Zeuner M, Straub RH, Rauh G, Albert ED, Scholmerich J, Lang B. Relapsing polychondritis: clinical and immunogenetic analysis of 62 patients. The Journal of Rheumatology. 1997;24(1):96-101.

9. Takagi D, Iwabuchi K, Iwabuchi C, et al. Immunoregulatory defects of V alpha $24 \mathrm{~V}+$ beta $11+$ NKT cells in development of Wegener's granulomatosis and relapsing polychondritis. Clinical and Experimental Immunology. 2004;136(3):591-600.

10. Goldring MB, Sandell LJ, Stephenson ML, Krane SM. Immune interferon suppresses levels of procollagen mRNA and type II collagen synthesis in cultured human articular and costal chondrocytes. The Journal of Biological Chemistry. 1986;261(19): 9049-9055.

11. Stabler T, Piette JC, Chevalier X, Marini-Portugal A, Kraus VB. Serum cytokine profiles in relapsing polychondritis suggest monocyte/macrophage activation. Arthritis and Rheumatism. 2004;50(11):3663-3667.

12. Hansson AS, Johansson AC, Holmdahl R. Critical role of the major histocompatibility complex and IL-10 in matrilin-1-induced relapsing polychondritis in mice. Arthritis Research and Therapy. 2004;6(5):R484-R491.

13. Ouchi N, Uzuki M, Kamataki A, Miura Y, Sawai T. Cartilage destruction is partly induced by the internal proteolytic enzymes and apoptotic phenomenon of chondrocytes in relapsing polychondritis. The Journal of Rheumatology. 2011;38(4):730-737.

14. Herman JH, O’Connor MP, Lieberman MA. Perturbation of a cartilage autocrine/paracrine basic fibroblast growth factor metabolic regulatory network by osteoarthritic synovial tissue. American Journal of Therapeutics. 1996;3(1):52-62.

15. Bradley DS, Das P, Griffiths MM, Luthra HS, David CS. HLADQ6/8 double transgenic mice develop auricular chondritis following type II collagen immunization: a model for human relapsing polychondritis. Journal of Immunology (Baltimore, Md.: 1950). 1998;161(9):5046-5053.

16. Compton N, Buckner J, Harp K, Raugi G. Polychondritis. Medscape reference. Available from: http://emedicine.medscape.com/ article/331475-overview. Accessed on April 15, 2016.

17. Berger R. Polychondritis resulting from intravenous substance abuse. The American Journal of Medicine. 1988;85(3):415-417.

18. van Eden W, Holoshitz J, Nevo Z, Frenkel A, Klajman A, Cohen IR. Arthritis induced by a T-lymphocyte clone that responds to Mycobacterium tuberculosis and to cartilage proteoglycans. Proceedings of the National Academy of Sciences of the United States of America. 1985;82(15):5117-5120.

19. Alissa H, Kadanoff R, Adams E. Does mechanical insult to cartilage trigger relapsing polychondritis? Scandinavian Journal of Rheumatology. 2001;30(5):311.

20. Furer V, Wieczorek RL, Pillinger MH. Bilateral pinna chondritis preceded by glucosamine chondroitin supplement initiation. Scandinavian Journal of Rheumatology. 2011;40(3):241-243.

21. Frances C, el Rassi R, Laporte JL, Rybojad M, Papo T, Piette JC. Dermatologic manifestations of relapsing polychondritis. A study of 200 cases at a single center. Medicine. 2001;80(3):173-179. 
22. Várkonyi J, Jakab L, Zalatnay A, Nagy P, Vámoss R, Szombathy T.: Polychondritis Terminating in Eosinophilic Leukemia. Pathol Oncol Res. 1997;3(2):135-138.

23. Eaton WW, Pedersen MG, Atladottir HO, Gregory PE, Rose NR, Mortensen PB. The prevalence of 30 ICD-10 autoimmune diseases in Denmark. Immunol Res. 2010;47(1-3):228-231.

24. Sharma A, Gnanapandithan K, Sharma K, Sharma S. Relapsing polychondritis: a review. Clinical Rheumatology. 2013;32(11): 1575-1583.

25. Sharma A, Law AD, Bambery P et al. Relapsing polychondritis: clinical presentations, disease activity and outcomes. Orphanet J Rare Dis. 2014;9:198.

26. Botey A, Navasa M, del Olmo A, et al. Relapsing polychondritis with segmental necrotizing glomerulonephritis. Am J Nephrol. 1984;4(6):375-378.

27. Choy EH, Chikanza IC, Kingsley GH, Panayi GS. Chimaeric antiCD4 monoclonal antibody for relapsing polychondritis. Lancet. 1991;338(8764):450.

28. Kemta Lekpa F, Kraus VB, Chevalier X. Biologics in relapsing polychondritis: a literature review. Semin Arthritis Rheum. 2012;41(5): $712-719$.

29. World Health Organization. ICD-10 : international statistical classification of diseases and related health problems: tenth revision. Geneva: Geneva: World Health Organization; 1992.

30. Michet CJ. Treatment of relapsing polychondritis. 2013; http:/www. uptodate.com/contents/treatment-of-relapsing-polychondritis. Accessed on April 15, 2016.
31. Hidalgo CA, Blumm N, Barabasi AL, Christakis NA. A dynamic network approach for the study of human phenotypes. PLoS Comput Biol. 2009;5(4):e1000353.

32. Kent PD, Michet CJ, Jr., Luthra HS. Relapsing polychondritis. Curr Opin Rheumatol. 2004;16(1):56-61.

33. Kaplan EL, Meier P. Nonparametric Estimation from Incomplete Observations. J Am Stat Assoc. 1958;53(282):457-481.

34. Link CL. Confidence intervals for the survival function using Cox's proportional-hazard model with covariates. Biometrics. 1984;40(3):601-609.

35. Shoenfeld Y, Tincani A, Gershwin ME. Sex gender and autoimmunity. J Autoimmun. 2012;38(2-3):J71- J73.

36. Eaton WW, Rose NR, Kalaydjian A, Pedersen MG, Mortensen PB. Epidemiology of autoimmune diseases in Denmark. J Autoimmun. 2007;29(1):1-9.

37. Hungarian Meteorological Service (HMS). Hungary sunlight, sunshine duration and cloud cover conditions. Available from: http://met.hu/ eghajlat/magyarorszag_eghajlata/altalanos_eghajlati_jellemz es/sugarzas/. Accessed on April 152016.

38. National Public Health Service. [Drinking Water Quality, 2012] Ivóvíz minőség, 2012. Available from: https:/www.antsz.hu/data/cms52115/ Ivovizminoseg_2012_honlapra_20140404.pdf. Accessed on April 15, 2016.

39. Lindgren A, Danielsson BR, Dencker L, Vahter M. Embryotoxicity of arsenite and arsenate: distribution in pregnant mice and monkeys and effects on embryonic cells in vitro. Acta Pharmacol Toxicol (Copenh). 1984;54(4):311-320. 


\section{Supplementary materials \\ Hazard ratio analysis}

The Kaplan-Meier approach presented in the main text of the paper provides a cumulative view of the survival rate of the disease. Another frequently used approach is to look at the hazard function, which assesses the instantaneous risk of death at a point of time, conditional on survival at that time. The hazard ratio modeling examines the relationship between survival and one or more predictors. We calculated the hazard ratios for the relapsing polychondritis survival with the Cox proportional hazards ratio model ${ }^{1}$ using the age groups of the patients as a possible predictor variable. ${ }^{2}$

The baseline hazard function with a monotonic increasing trend is shown in Figure S1. The hazard ratio coefficient is 1.8 $(95 \%$ confidence interval $=1.36-2.38)$ which is significantly larger than $1(P=3 \mathrm{e}-5)$, meaning that age is a significant factor in the hazard of death.

In Figure S2, we examine the estimated distribution of survival times, and how the estimated survival depends upon age. Each estimate is accompanied by a point-wise $95 \%$ confidence envelope. The survival drops much faster for patients in the older age groups.

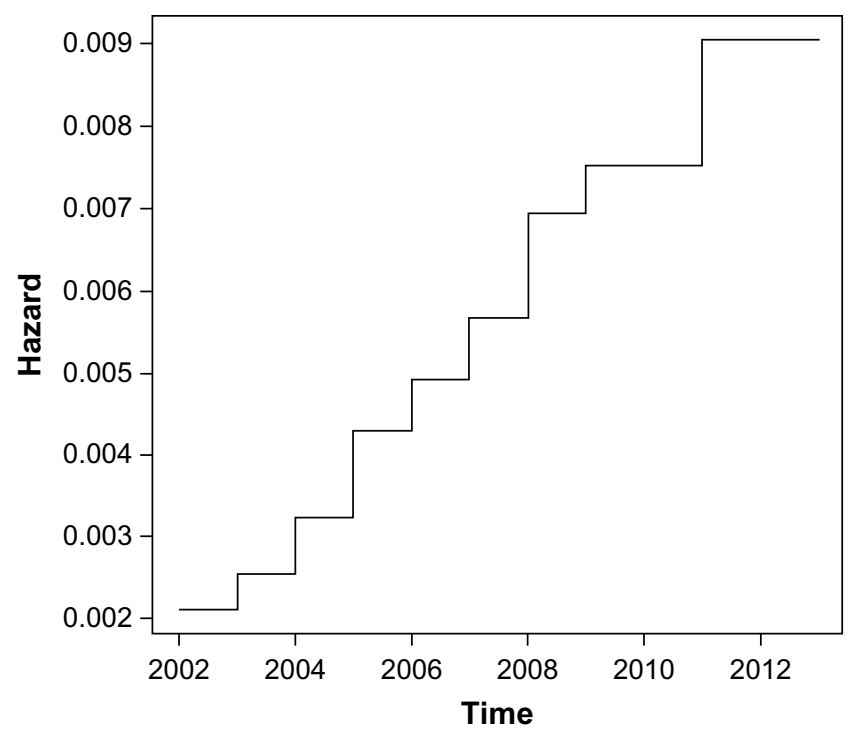

Figure SI Baseline hazard function for the patients with relapsing polychondritis.

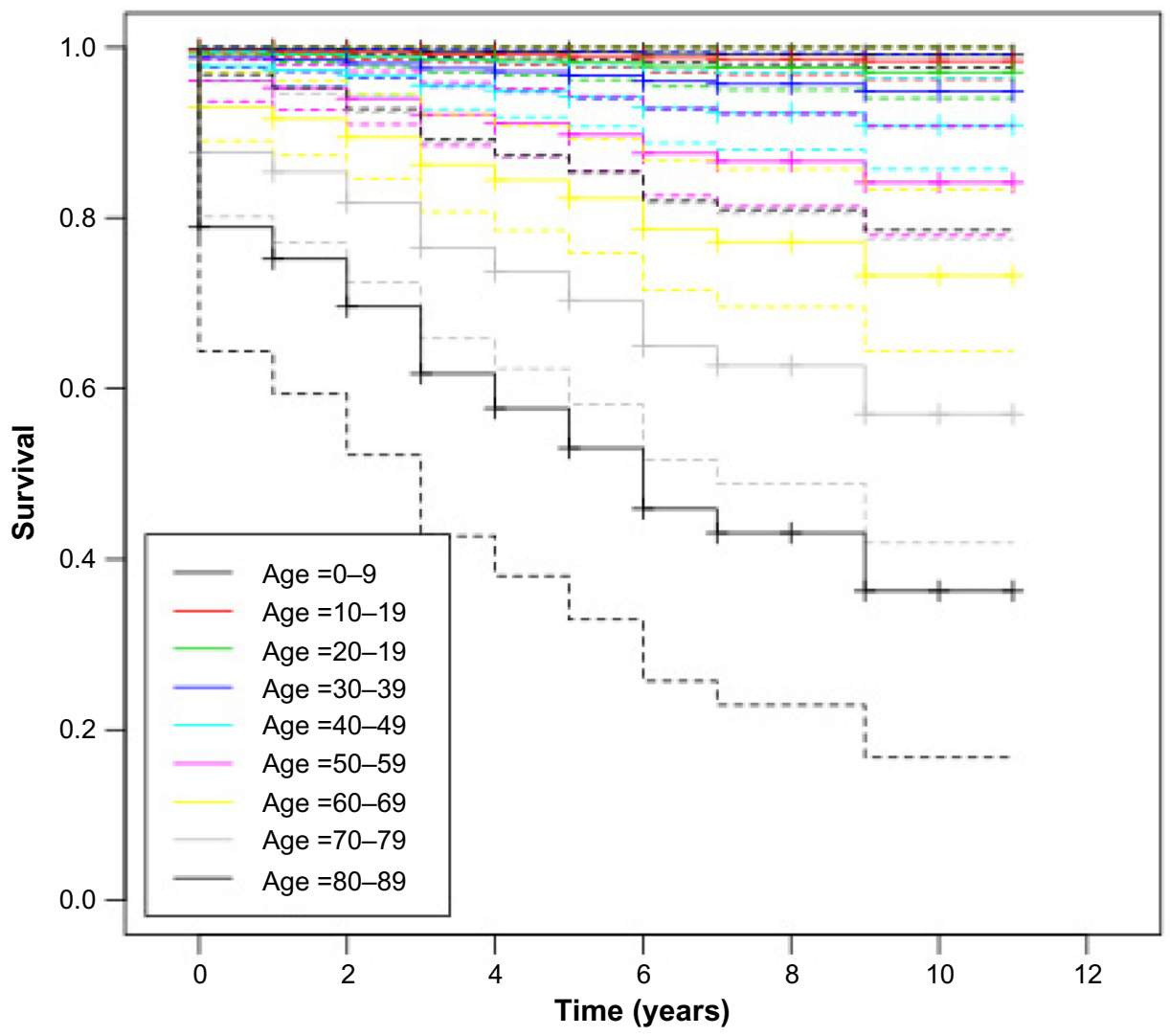

Figure S2 Survival functions with 95\% confidence intervals for the age groups (in years) of patients with relapsing polychondritis. 
Table SI List of ICDIO codes of diseases

\begin{tabular}{ll}
\hline ICDI0 & Disease \\
\hline II0 & Hypertonia \\
M47 & Spondylosis \\
H52 & Disorders of refraction and accommodation \\
M54 & Back pain \\
M5I & Other intervertebral disc disorders \\
E07 & Thyroid dysfunction \\
EII & Type 2 diabetes \\
C00-D09 & Malignant cancer \\
M35 & Sjögren syndrome \\
M05-M06 & Rheumatoid arthritis \\
M32 & Systemic lupus erythematosis \\
E05 & Thyrotoxicosis \\
H20 & Iridocyclitis \\
L40 & Psoriasis \\
J0I-J22 & Respiratory infections (sinusitis, rhinitis, bronchitis, \\
& influenza, pneumonia) \\
B30 & Common infectious conjunctivitis \\
MI6 & Coxarthrosis \\
L30 & Dermatitis \\
I25 & Ischemic heart disease \\
E78 & Lipoprotein disorders \\
F30-F39 & Depression \\
F4I & Anxiety problems \\
A00-B99 & Certain infectious and parasitic diseases \\
S00-T88 & Injury, poisoning and certain other consequences of \\
& external causes \\
\hline
\end{tabular}

\section{References}

1. Cox DR, Oakes D. Analysis of Survival Data. London: Chapman and Hall; 1984.

2. Therneau TM, Grambsch PM. Modeling Surival Data: Extending the Cox Model. New York: Springer; 2000.
Clinical Epidemiology

\section{Publish your work in this journal}

Clinical Epidemiology is an international, peer-reviewed, open access, online journal focusing on disease and drug epidemiology, identification of risk factors and screening procedures to develop optimal preventative initiatives and programs. Specific topics include: diagnosis, prognosis, treatment, screening, prevention, risk factor modification,

Submit your manuscript here: http://www.dovepress.com/clinical-epidemiology-journal

\section{Dovepress}

systematic reviews, risk \& safety of medical interventions, epidemiology \& biostatistical methods, and evaluation of guidelines, translational medicine, health policies \& economic evaluations. The manuscript management system is completely online and includes a very quick and fair peer-review system, which is all easy to use. 